\title{
REINCIDÊNCIA DE GRAVIDEZ NA ADOLESCÊNCIA
}

Mikaely Thays Oliveira Pereira ${ }^{1}$, Leticia Vioto Milão ${ }^{1}$, Isabel Cristina Belasco ${ }^{2}$

${ }^{1}$ Discente da Faculdade de Ciências da Saúde de Presidente Prudente - Curso de Enfermagem - UNOESTE. ${ }^{2}$ Docente da Faculdade de Ciências da Saúde de Presidente Prudente - Curso de Enfermagem - UNOESTE. E-mail: isabel.belasco@unoeste.br

\section{RESUMO}

Hoje em dia existe no Brasil mais de um bilhão de pessoas com idade entre 10 e 19 anos, esse numero representa quase $20 \%$ da população mundial, compreendendo no Brasil 35 milhões de adolescentes de ambos os sexos. A gravidez pode ser fruto da falta de informação adequada sobre saúde reprodutiva e métodos contraceptivos, mas também pode estar associada à falta de acesso a eles. Quando não se tem o acompanhamento pós-parto, a reincidência da gravidez ocorre em torno de $30 \%$ no primeiro ano, $50 \%$ no segundo ano e até $61 \%$ cinco anos após a primeira gravidez. É evidente a necessidade de uma melhor preparação/formação dos profissionais de saúde e de educação, em particular dos enfermeiros. O Objetivo deste trabalho é descrever os fatores de risco da reincidência da gravidez na adolescência e suas consequências com foco na enfermagem e a importância do planejamento familiar.

Palavras chave: Gravidez, Adolescência, Reincidência, Planejamento Familiar, Enfermagem.

\section{INTRODUÇÃO}

De acordo com os critérios da Organização Mundial de Saúde (OMS) a adolescência é o período compreendido entre 10 a 19 anos e, segundo o Estatuto da Criança e do Adolescente no Brasil - ECA esta fase é determinada dos 12 aos 18 anos de idade cronológica. Este período caracteriza o começo da vida reprodutiva e é marcado por alterações fisiológicas e psicológicas no corpo humano. Tais transformações e adaptações devem decorrer de forma saudável, para que não traga malefícios ao adolescente, tanto relacionado à sua saúde física quando psicológica e social (NERY et al, 2011).

Hoje em dia existe no Brasil mais de um bilhão de pessoas com idade entre 10 e 19 anos, esse numero representa quase $20 \%$ da população mundial, compreendendo no Brasil 35 milhões de adolescentes de ambos os sexos (NERY et al, 2011).

A preocupação com a gravidez na adolescência vem de longa data, mas estudos relacionados à sua reincidência não recebeu devida importância durante muito tempo, o que é lamentável, quando se percebe que a reincidência da gravidez em adolescentes vem aumentando, e junto com ela, vem o abandono ou não adesão do pré-natal, seja por desconhecimento de sua importância ou por falta de interesse, e os riscos que essa gravidez trás consigo (MANFRÉ; QUEIROZ; MATTHES, 2010). 
Quando não se tem o acompanhamento pós-parto, a reincidência da gravidez ocorre em torno de $30 \%$ no primeiro ano, $50 \%$ no segundo ano e até $61 \%$ cinco anos após a primeira gravidez, sendo que cerca de $40 \%$ dessas adolescentes tinha engravidado mais de uma vez durante esse período de pesquisa (MANFRÉ; QUEIROZ; MATTHES, 2010).

Dentre os fatores que influenciam as adolescentes a ficarem grávidas estão a não adesão ou uso incorreto dos métodos contraceptivos, sendo que grande parte das pessoas se sente confiante com os conhecimentos que julga ter; o inicio precoce da vida sexual e conhecimento insuficiente sobre anatomia do corpo e sexualidade, percebendo-se que quanto maior a idade, escolaridade e intimidade com os parceiros maiores são seus conhecimentos relacionados à anatomia, inclusive sobre período fértil; família desestruturada, uso de drogas e álcool por familiares, gravidez da mãe também precoce, número de parceiros, ausência de apoio em gestação anterior e problemas emocionais como; adolescentes com baixa autoestima, dificuldades de relacionamento familiar, ausência dos pais e carência afetiva (MANFRÉ; QUEIROZ; MATTHES, 2010).

A Estratégia da Saúde da Família (ESF) foi implantada para reorganizar o Sistema Único de Saúde. Reforça ainda os princípios da territorialidade, da integralidade na atenção às famílias sob sua responsabilidade e o trabalho em equipe multidisciplinar, o que possibilita uma atenção qualificada, focada na promoção da saúde com o fortalecimento de ações intersetoriais e o estímulo à participação da comunidade (SILVA; SILVA; BOUSSO, 2011).

O Objetivo deste trabalho é descrever os fatores de risco da reincidência da gravidez na adolescência e suas consequências com foco na enfermagem e a importância do planejamento familiar.

\section{METODOLOGIA}

Todo o estudo foi realizado por pesquisas com levantamento de conteúdo nas bases científicas Scientific Eletronic Library Online - SCIELO, Biblioteca Virtual em Saúde - BVS e também em artigos do GOOGLE ACADÊMICO, através destas bases foram feitas resenhas/resumos com as principais informações de cada artigo escolhido.

Esta seleção foi feita no período de Nov/2012 a Ago/2013. A escolha dos mesmos foi feita através de termos relacionados ao assunto, utilizando como palavras chave: Gravidez, Adolescência, Reincidência, Planejamento Familiar, Enfermagem.

A análise crítica dos dados foi feita por meio de leitura e levou-se em consideração a 
autenticidade e proveniência dos artigos utilizados.

E por fim, todo o material coletado foi organizado por autor, artigo, importância relevante ao trabalho e fonte. Todos os dados importantes foram digitalizados para formação do Trabalho de Conclusão de Curso, que ficou organizado conforme a estrutura pré-estabelecida.

\section{REFERENCIAL TEÓRICO}

\section{Sexualidade na Adolescência}

A sexualidade é algo que se constrói e se aprende, sendo parte necessária para o desenvolvimento da personalidade, e tem a capacidade de interferir no processo de aprendizagem, na saúde mental e física do indivíduo. A construção de uma identidade sexual é uma etapa da adolescência que depende não só da fase de desenvolvimento em que se encontra como do contexto familiar e social em que vive e de suas próprias experiências amorosas. Assim, entendemos que toda essa transformação biológica e psicológica também pode acarretar várias mudanças na convivência social do adolescente (BRÊTAS et al, 2011).

Segundo Marola, Sanches e Cardoso (2011):

É importante ressaltar que os adolescentes e os jovens têm direito de ter acesso a informações e educação em saúde sexual e saúde reprodutiva e de ter acesso a meios e métodos que os auxiliem a evitar uma gravidez não planejada e prevenirem-se contra as doenças sexualmente transmissíveis/HIV-AIDS, respeitando-se a sua liberdade de escolha.

Um pouco diferente do que vemos hoje em dia, no passado a repressão era suficiente para conter a expressão da sexualidade dos adolescentes. Já nos dias atuais, com a facilidade de acesso às informações, as conquistas do espaço feminino, um novo contexto sócio, político e econômico, a adolescência passa a incorporar novas características, que contribuem significativamente para a iniciação sexual precoce deste grupo, seja por curiosidade, pressão do grupo de amigos, falta de coragem para dizer não, paixão e até mesmo o uso de drogas e álcool (COSTA; PRADO, 2001).

\section{Gravidez na Adolescência e sua Reincidência}

A adolescência é um período confuso, de contradições, de formação da identidade e da autoestima; uma passagem na qual se deixa de ser criança para se tornar adulto, repleto de responsabilidades e cobranças; um mundo desejado pela sensação da liberdade a ser adquirida, mas também tão temido por não saber o que esta por vir (MOREIRA et al, 2008).

A adolescência é uma fase muitas vezes bastante conturbada em razão de várias 
descobertas, alterações percebidas na fisiologia do organismo, nos pensamentos e nas atitudes desses jovens. Na realidade brasileira, muitas vezes a adolescente, além dos conflitos próprios da faixa etária, vê-se com outras questões conflituosas, como a ocorrência de uma gravidez não planejada (MOREIRA et al, 2008).

A gravidez é um período que trás grandes mudanças na vida de uma mulher; essa fase pode acabar gerando dúvidas, sentimentos de fragilidade, insegurança e ansiedade (MOREIRA et al, 2008).

A dificuldade em relação às mudanças provocada pela vinda de um bebê não se resume às constantes mudanças psicológicas e bioquímicas, pois os fatores socioeconômicos também são fundamentais. Essas adolescentes muitas vezes, além de assumir uma gravidez indesejada, tem medo de enfrentar a gravidez perante a família ou companheiro, medo da reação dos pais diante da gravidez, e aumenta as dificuldades socioeconômicas em vista que, uma criança também gera custos. Sendo assim, se deparam com um sentimento de medo e insegurança, podendo muitas vezes se deparar com a depressão ou procurar outras formas de "resolver o problema" como, por exemplo, o aborto (MOREIRA et al, 2008).

Quanto mais precocemente ocorre a gravidez, maiores são as chances de ocorrer uma segunda gestação; no entanto, quando a adolescente assume um compromisso de união com o pai de seu filho, as chances de uma nova gravidez diminuem em relação a aquelas que não permanecem com o companheiro, portanto, a mudança do parceiro se constituiu, em uma condição de risco para a reincidência da gravidez, aumentando em cerca de $40 \%$ a chance de uma nova gestação (BRUNO et al, 2009).

Ainda segundo Bruno, et al ( 2009 ) esses dados se tornam ainda mais importantes quando se sabe que a gravidez diminui a probabilidade das adolescentes concluírem os estudos e ter um emprego estável para ser economicamente autossuficiente. Além de favorecer a exclusão social, o que também facilita uma nova gestação.

\section{Riscos e Consequências}

Os riscos de gestação na adolescência não são apenas devido ao fator idade, existem riscos biológicos, porém os riscos psíquicos e sociais também são bastante importantes. Quanto ao fator idade, podemos considerar duas faixas etárias, a adolescência precoce de 11 a 15 anos e a tardia 
de 16 a 19 anos. È na primeira fase que ocorrem mais riscos. Esta faixa etária coincide também com a maior não aceitação da gestação e início do pré-natal tardio, o que acaba acarretando falta de orientação alimentar, e de cuidados em geral, além de apoio psicossocial (COSTA; HEILBORN, 2006).

Os problemas encontrados mais frequentemente são: doença hipertensiva específica da gravidez (DHEG), anemia, infecção urinária e toxemia gravídica para as mulheres, e mortalidade perinatal, baixo peso ao nascer e prematuridade para os bebês (COSTA; HEILBORN, 2006).

Além dos riscos biológicos, as mães adolescentes também enfrentam os riscos psicossociais. Quando uma jovem engravida precocemente, isso pode significar uma grande perda de oportunidades. A grande maioria das garotas acaba deixando os estudos, o que consequentemente pode levar a sentimentos de diminuição de autoestima, depressão, conflitos com a família por entenderem tal ato como inaceitável e vergonhoso, e algumas vezes até em pensamentos de suicídio (COSTA; HEILBORN, 2006).

\section{O papel da Enfermagem no Planejamento Familiar}

O Planejamento Familiar tem por objetivo a propagação da doutrina da paternidade consciente e responsável e o oferecimento da instrução e de métodos contraceptivos seguros aos casais para que eles voluntariamente planejem seus filhos dentro de suas possibilidades econômicas, sociais e psicológicas (BERLOFI et al, 2006).

Entretanto faz-se necessário que esses profissionais sejam preparados para assumir esta função. A saúde sexual do adolescente precisa ser discutida no contexto, dependem de uma série de condições socioculturais favoráveis, como adequadas condições de vida, serviços de saúde de qualidade, pois existem poucos programas destinados a essa faixa etária da população, ressaltando ainda que cerca de $70 \%$ das adolescentes utilizam os métodos por, no máximo, seis meses, mesmo mantendo um relacionamento superior a esse período. Sendo assim a enfermagem precisa ser capaz de esclarecer as dúvidas e difundir informações sobre este assunto, além de firmar-se como profissional presente na vida das pessoas, podendo também desenvolver um trabalho interdisciplinar em sua unidade de saúde (BERLOFI et al, 2006).

O enfermeiro como profissional capacitado para assistir ao indivíduo em todas as etapas de vida, necessita estar inserido no Programa de Educação Sexual das escolas, promovendo ações e programas voltados para a saúde do adolescente e sua família os quais devem atender as reais necessidades de ambos. É fundamental que todos, governo, profissionais de saúde e de educação, 
família, escola e sociedade sejam ativos na educação sexual dos adolescentes, não só para exercer sua sexualidade, mas, principalmente para exercer seus direitos com responsabilidade, sendo respeitados e respeitando os outros (BERLOFI et al, 2006).

\section{CONCLUSÃO}

Os dados da pesquisa apontam para a questão da vulnerabilidade vivida pelas adolescentes, o que as colocam cada vez mais próximas do risco para a gravidez precoce e a reincidência de gravidez.

É necessário repensar a questão da gravidez na adolescência e sua reincidência como um sério problema social e a necessidade de se valorizar o trabalho educativo junto às adolescentes, nas escolas, serviços públicos de saúde, inserindo pais/família neste processo educativo, com enfoque nas questões de sexualidade e acolhimento quando uma gravidez já se ocorreu.

A gravidez pode ser fruto da falta de informação adequada sobre saúde reprodutiva e métodos contraceptivos, mas também pode estar associada à falta de acesso a eles. É evidente a necessidade de uma melhor preparação/formação dos profissionais de saúde e de educação, em particular dos enfermeiros, na área que abrange a sexualidade, para que possam desenvolver programas de saúde especialmente voltados para os adolescentes ou até mesmo programas voltados para os pais de adolescentes, pois muitas vezes não há comunicação por não saberem como abordar seus filhos ou até mesmo por não obterem conhecimentos a respeito do assunto.

Uma forma de esses profissionais estarem mais preparados para atender essa população, atuando de forma mais efetiva e obtendo resultados mais satisfatórios, seriam preparar os alunos ainda na graduação, trabalhando tanto com disciplinas especifica como desenvolvendo atividades na pratica, sempre visando o trabalho interdisciplinar, que além de ajudar a desenvolver a autoconfiança ainda na graduação, forma um enfermeiro diferenciado para atuar de forma autônoma e criativa.

Esses ainda devem propiciar a abertura de espaços para discussão de temáticas, inclusive sobre a prevenção da gravidez precoce e reincidência, com troca de experiência entre pares e supervisão de profissionais no encaminhamento das discussões, com o objetivo de apoiar os adolescentes em suas dúvidas, medos e dificuldades.

\section{REFERÊNCIAS}

BERLOFI, L. M.; ALKMIN, E. L. C.; BARBIERI, M.; GUAZZELLI, C. A. F.; ARAÚJO F. F. Prevenção da reincidência de gravidez em adolescentes: efeitos de um Programa de Planejamento Familiar. Acta 
Paul Enferm. 2006;19(2):196-200. Disponível em: http://www.scielo.br/pdf/ape/v19n2/a11v19n2.pdf Acesso em: Jan/2013.

BRANDÃO, E. R.; HEILBORN, M. L. Sexualidade e gravidez na adolescência entre jovens de camadas médias do Rio de Janeiro, Brasil. Cad. Saúde Pública, Rio de Janeiro, 22(7):1421-1430, jul, 2006. Disponível em $\quad$ http://www.scielo.br/scielo.php?script=sci arttext\&pid=S0102311X2006000700007 Acesso em: Nov/2012.

BRÊTAS, J. R. S.; et al. Aspectos da sexualidade na adolescência. Ciência \& Saúde Coletiva, 16(7): 3221-3228, 2011. Disponível em http://www.scielo.br/scielo.php?pid=S1413$81232011000800021 \&$ script=sci arttext Acesso em: Nov/2012.

BRUNO, Z. V. et al. Reincidência de gravidez em adolescentes. Rev Bras Ginecol Obstet. Fortaleza (CE), Brasil. 2009; 31(10):480-4. Disponível em: http://www.scielo.br/scielo.php?pid=S010072032009001000002\&script=sci arttext Acesso em: Nov/2012.

CANO, M. A. T.; FERRIANI, M. G. C.; GOMES, R. Sexualidade Na Adolescência: Um Estudo Bibliográfico. Rev. latino-am. Enfermagem - Ribeirão Preto - v. 8 - n. 2 - p. 18-24 - abril 2000. Disponível em: http://www.scielo.br/pdf/rlae/v8n2/12413 Acesso em: Nov/2012.

COSTA, F. C.; PRADO, S. R. L. A. O papel do enfermeiro na orientação sexual de adolescentes no ambiente escolar. Rev Enferm UNISA 2001; 2: 80-3. Disponível em http://www.unisa.br/graduacao/biologicas/enfer/revista/arquivos/2001-17.pdf Acesso em: Nov/2012.

COSTA, T. J. N. M.; HEILBORN. M. L. Gravidez Na Adolescência E Fatores De Risco Entre Filhos De Mulheres Nas Faixas Etárias De 10 A 14 E 15 A 19 Anos Em Juiz De Fora, MG. Revista APS, v.9, n.1, p. 29-38, jan./jun. 2006. Disponível em: http://www.ufjf.br/nates/files/2009/12/Gravidez.pdf Acesso em: Jan/2013.

Estatuto da criança e do adolescente. Senado Federal. Brasília: 2005.

GIL, A. C. Como elaborar projetos de pesquisa. 4. ed. São Paulo: Atlas, 2002.

MANFRÉ, C. C.; QUEIRÓZ, S. G.; MATTHES, Â. C. S. Considerações atuais sobre gravidez na adolescência. R. bras. Med. Fam. e Comun., Florianópolis, v. 5, n. 17, p. 48-54, jan./dez. 2010. Disponível Em: http://www.rbmfc.org.br/index.php/rbmfc/article/view/205/155 Acesso em: Ago/2013.

MAROLA, C. A. G.; SANCHES, C. S. M.; CARDOSO, L. M. Formação de conceitos em sexualidade na adolescência e suas influências. Psic. da Ed., São Paulo, 33, 20 sem. de 2011, pp. 95-118. Disponível em http://pepsic.bvsalud.org/scielo.php?pid=S141469752011000200006\&script=sci arttext Acesso em: Nov/2012.

MOREIRA, T. M. M.; et al. Conflitos vivenciados pelas adolescentes com a descoberta da gravidez. Rev. esc. enferm. USP vol.42 no. 2 São Paulo Jun 2008. Acesso em: http://www.scielo.br/scielo.php?script=sci arttext\&pid=S0080-62342008000200015 Acesso em: Nov/2012. 
NERY, I. S.; et al. Reincidência da gravidez em adolescentes de Teresina, PI, Brasil. Rev Bras Enferm, Brasília 2011 jan-fev; 64(1): 31-7. Disponível em: http://www.scielo.br/scielo.php?pid=S0034-71672011000100005\&script=sci arttext Acesso em: Nov/2012.

SILVA, M. C. L. S. R.; SILVA, L.; BOUSSO, R. S. A abordagem à família na Estratégia Saúde da Família: uma revisão integrativa da literatura. Rev. esc. enferm. USP vol.45 no.5 São Paulo Oct. 2011. Disponível em $\quad$ http://www.scielo.br/scielo.php?script=sci arttext\&pid=S0080-

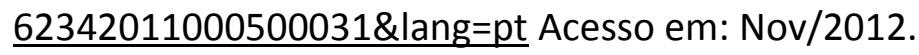

